\title{
Efficacy and Effectiveness of Physical Therapy in Enhancing Postural Control in Children with Cerebral Palsy
}

\author{
Susan R. Harris and Lori Roxborough \\ School of Rehabilitation Sciences, Faculty of Medicine, University of British Columbia, Vancouver, \\ B.C. V6T 2B5 Canada, ${ }^{2}$ Sunny Hill Health Centre for Children, Vancouver, B.C. V5M 3E8 Canada
}

\begin{abstract}
SUMMARY
The purpose of this article was to conduct a systematic review of studies that examined the efficacy and effectiveness of postural control intervention strategies for children with $\mathrm{CP}$. Only physical therapy interventions were included, e.g. adaptive seating devices, ankle foot orthoses, neurodevelopmental treatment. A multifaceted search strategy was employed to identify all potential studies published between 1990 and 2004. The search strategy included electronic databases, reference list scanning, author and citation tracking of relevant studies, and hand searching of pediatric physical therapy journals and conference proceedings. Twelve studies (1991-2004), comprising ten group design studies and two single subject studies, met our inclusion criteria. A variety of age ranges and severity of children with cerebral palsy $(n=132)$ participated in the studies. The study quality scores ranged from 2 to 7 (total possible range of 0 to 7) with a median score of 5.5 and a mode of 6 . As was true in an earlier systematic review on adaptive seating, most of the 12 'experimental' studies published since 1990 that were aimed at evaluating the effectiveness of postural control
\end{abstract}

Reprint requests to: Susan R. Harris, School of Rehabilitation Sciences, UBC, T-325 Wesbrook Mall, Vancouver, B.C. V6T 2B5 Canada; email: shar@interchange.ubc.ca strategies provided lower levels of evidence, i.e. Sackett Levels III to V. Additional studies with stronger designs are needed to establish that postural control interventions for children with $\mathrm{CP}$ are effective.

\section{INTRODUCTION}

A decade ago, Roxborough (1995) published a systematic review of research evidence on the efficacy and effectiveness of adaptive seating in children with cerebral palsy (CP). Of the eight studies included in that review, the three with the strongest methodology supported the efficacy of some forms of adaptive seating in attaining shortterm improvement in pulmonary function, active trunk extension, and improved performance on the Bayley Mental Scale. Less rigorous studies indicated that certain forms of seating had no effect on reaching, self-feeding, or drinking, but that other seating methods can be effective in improving sitting posture, vocalization, and some oral-motor skills. Because adaptive seating has been one of the most commonly studied interventions for enhancing postural control and postural alignment in children with $\mathrm{CP}$, we have updated and expanded our earlier review to include other physical therapy interventions designed to influence postural control, e.g. balance training, neurodevelopmental treatment (NDT), orthoses, etc.

Although an increasing body of research has been published on postural control in children with 
$\mathrm{CP}$, many of those studies have been observational, descriptive, or predictive (e.g. Brogren, HaddersAlgra, \& Forssberg, 1998; Brogren, Forssberg, \& Hadders-Algra, 2001; van der Heide et al., 2004) rather than experimental. In other words, very few studies have examined the effectiveness of physical therapy interventions in enhancing postural control in children with CP. We begin by defining important terms used within this review.

Postural control "involves the control of the body's position in space in order to obtain stability and orientation" (Massion, 1998). The purposes of that control are to maintain equilibrium and orientation in sitting and standing (Horak, 1992; Shumway-Cook \& Woollacott, 1993). Effectiveness studies assess the "benefits of an intervention as tested under 'real-world' conditions, often using quasi-experimental methods", whereas efficacy refers to "benefits of an intervention under controlled experimental conditions, usually with a control group" (Portney \& Watkins, 2000). A systematic review is "a rigorous and explicit research method that aims to locate, appraise and synthesize the available research evidence pertaining to a specific research question and to evaluate the quality of the studies using predetermined criteria" (Hammell \& Carpenter, 2004).

At a 1990 consensus conference on the efficacy of physical therapy in the management of $\mathrm{CP}$, the improvement of postural control was noted to be a potentially promising outcome of physical therapy intervention (Campbell, 1990). As the evidence was suggestive only, a call for further research was issued to substantiate this finding. The purpose of our article is to review the research published since the consensus conference to determine the extent to which the effectiveness of physical therapy interventions for children with $\mathrm{CP}$ have been demonstrated to improve postural control.

No review on this topic has been published since the consensus conference and no in-progress review is registered in the Ongoing Reviews Database of the Centre for Reviews and Dissemination.

\section{METHODS}

\section{Data sources}

A multifaceted search strategy was employed to identify all potential studies published between 1990 and 2004. The strategy included searching electronic databases, reference list scanning, author and citation tracking of relevant studies, and hand searching of pediatric physical therapy journals and conference proceedings.

The electronic databases searched include MEDLINE, CINAHL, EMBASE, PsycINFO, SportDiscus, Cochrane Database of Systematic Reviews, Cochrane Controlled Trials Register, PEDro, DARE, and Dissertation Abstracts using the search terms cerebral palsy and posture or postural control or balance. The search was limited to children and to English-language articles. The journals that were hand searched include Pediatric Physical Therapy, Gait and Posture, Developmental Medicine, and Child Neurology, in addition to abstracts of the Gait and Posture conference and the American Academy of Cerebral Palsy and Developmental Medicine.

\section{Study selection}

The titles and abstracts of the articles identified were screened independently by the two authors (using abstract screening forms designed for the study) to determine whether they met the inclusion and exclusion criteria for the review. Exclusion criteria were set for co-interventions (medication or surgery) that might have influenced the outcome and duplicate reports of studies. Inclusion criteria were set for the following: 
1. population (children with $\mathrm{CP}$ between 0 and 19 years of age);

2. intervention (physical therapy strategy involving motor therapies, balance training, and assistive devices, including adaptive seating, splints, orthoses, or home programs);

3. outcome (measurement of change in postural control including clinical balance measures, EMG patterns of muscle coordination, kinematics or center of pressure movements); and

4. study type (intervention study).

Articles not clearly excluded by both reviewers during the abstract-screening process went on to full article review to determine whether all inclusion criteria were met. Reviewer differences after full article screening were resolved through discussion and consensus.

\section{Data extraction}

A data extraction form was developed for the study to address the study questions, the study quality, and the strength of the evidence. The extraction form was used to record design type, sample size, participant characteristics, intervention characteristics, outcome measures, results, and quality assessment criteria. To summarize the strength of the evidence from a variety of research designs, we used two evidence classification systems. For characterizing the level of group designs, Sackett and colleagues' (Sackett et al., 2000) more recent levels of evidence were used to grade the strength of the evidence contributed by the study design from Level I (strongest evidence) to Level V (weakest evidence) (see Table 1). An earlier version of Sackett's levels (1986) was used to rate the strength of the evidence for physical therapy interventions at the 1990 consensus conference (Campbell, 1990). These levels have been reported in subsequent reviews of inter- ventions, such as physiotherapy (Siebes et al., 2002) and botulinum toxin (Boyd \& Hays, 2001) for children with CP. The main difference between the recent and earlier evidence levels is the addition of systematic reviews and the creation of a subcategory option within each level. For the present review, the main category levels were used only for the group studies. A parallel evidence hierarchy, developed for evidence summaries conducted by the American Academy of Cerebral Palsy and Developmental Medicine (AACPDM), was used to rate single subject designs (see Table 2). Both reviewers independently extracted data from all included studies and resolved the discrepancies in data extraction by consensus.

\section{Study quality assessment}

The quality of the reported studies was assessed using the AACPDM Quality Assessment Scale (Butler C, 1998). This seven-item scale was developed for use with the wide range of study designs that are encountered in research in the area of developmental disabilities and has been used in reviews of interventions, such as neurodevelopmental therapy, conductive education, and adductor releases. A point is assigned for a positive response to each item. Scores are interpreted as Strong (6 or 7 ), Moderate (5), or Weak (4 or less). The reliability of this scale has not been reported, but the two reviewers independently applied the quality assessment criteria, discussed disagreements, and resolved their disagreements by consensus.

\section{AACPDM Study Quality Scale}

The conduct of the study is judged as Strong ('yes' score of 6 or 7), Moderate ('yes' score of 5), or Weak ('yes' score of $\leq 4$ ). The seven criteria for judging the quality of each study are presented in Table 3. 
TABLE 1

Levels of Evidence for Group Designs

\begin{tabular}{|c|c|}
\hline Level & Study Design \\
\hline Level I & $\begin{array}{l}\text { Systematic review of randomized controlled trials (RCT) } \\
\text { RCT with narrow confidence interval }\end{array}$ \\
\hline Level II & $\begin{array}{l}\text { RCT with wide confidence interval } \\
\text { Systematic review of cohort studies } \\
\text { Cohort study with concurrent control group }\end{array}$ \\
\hline Level III & $\begin{array}{l}\text { Systematic review of case-control studies } \\
\text { Case-control study }\end{array}$ \\
\hline Level IV & Case series \\
\hline Level V & Case study \\
\hline
\end{tabular}

TABLE 2

AACPDM Levels of Evidence for Single Subject Designs

\begin{tabular}{ll}
\hline Level & \multicolumn{1}{c}{ Study Design } \\
\hline Level I & N-of-1 randomized controlled trial \\
Level II & $\begin{array}{l}\text { ABABA design } \\
\text { Alternating treatments } \\
\end{array}$ \\
Multiple baseline across subjects \\
Level III & ABA \\
Level IV & AB \\
\hline
\end{tabular}


TABLE 3

Study Quality

\begin{tabular}{|c|c|c|c|c|c|c|c|c|}
\hline Study/First Author & $\begin{array}{l}\text { Inclusion/ } \\
\text { Exclusion }\end{array}$ & Adherence & Measure & Blinding & $\begin{array}{l}\text { Appropriate } \\
\text { Statistics }\end{array}$ & Dropouts & $\begin{array}{l}\text { Control } \\
\text { of Bias }\end{array}$ & Total \\
\hline \multicolumn{9}{|l|}{ Group Designs } \\
\hline $1991 \mathrm{Myhr}$ & $\sqrt{ }$ & $\sqrt{ }$ & $\sqrt{ }$ & & $\sqrt{ }$ & $\sqrt{ }$ & $\sqrt{ }$ & 6 \\
\hline 1997 Jonsdottir & $\sqrt{ }$ & & $\sqrt{ }$ & $\sqrt{ }$ & & $\sqrt{ }$ & $\sqrt{ }$ & 6 \\
\hline 1998 Butler & $\sqrt{ }$ & $\sqrt{ }$ & $\sqrt{ }$ & & $\sqrt{ }$ & $\sqrt{ }$ & $\sqrt{ }$ & 6 \\
\hline 2002 Kott & $\sqrt{ }$ & $\sqrt{ }$ & $\sqrt{ }$ & & $\sqrt{ }$ & $\sqrt{ }$ & $\sqrt{ }$ & 6 \\
\hline 2003 Wesdock & $\sqrt{ }$ & $\sqrt{ }$ & $\sqrt{ }$ & & $\sqrt{ }$ & $\sqrt{ }$ & $\sqrt{ }$ & 6 \\
\hline 1996 Reid & $\sqrt{ }$ & $\sqrt{ }$ & & & $\sqrt{ }$ & $\sqrt{ }$ & $\checkmark$ & 5 \\
\hline 1994 Pope & $\sqrt{ }$ & $\sqrt{ }$ & & & $\sqrt{ }$ & $\sqrt{ }$ & & 4 \\
\hline 1995 Myhr & $\sqrt{ }$ & & $\sqrt{ }$ & & $\sqrt{ }$ & & & 3 \\
\hline 1999 Kuczynski & & $\sqrt{ }$ & & & $\sqrt{ }$ & & & 2 \\
\hline 2000 Rennie & $\sqrt{ }$ & & & & & $\sqrt{ }$ & & 2 \\
\hline \multicolumn{9}{|l|}{ Single Subject Designs } \\
\hline 2002 Washington & $\sqrt{ }$ & $\sqrt{ }$ & $\sqrt{ }$ & $\sqrt{ }$ & $\sqrt{ }$ & $\sqrt{ }$ & $\sqrt{ }$ & 7 \\
\hline 2003 Shumway-Cook & $\sqrt{ }$ & $\sqrt{ }$ & & & $\sqrt{ }$ & $\sqrt{ }$ & $\sqrt{ }$ & 5 \\
\hline
\end{tabular}

Conduct of the study is judged as Strong (score of 6 or 7), Moderate (score 5), or Weak (score $\leq 4$ )

Were inclusion and exclusion criteria of the study population well described and followed?

Was the intervention well described and was there adherence to the intervention assignment? (for 2-group designs, was the control exposure also well described?)

Were the measures used clearly described, valid and reliable for measuring the outcomes of interest? Was the outcome assessor unaware of the intervention status of the participants (i.e. was there blind assessment)?

Did the authors conduct and report appropriate statistical evaluation including power calculations? Were dropouts/loss to follow-up reported and less than $20 \%$ ? For 2-group designs, was dropout balanced? Considering the potential with in the study design, were appropriate methods for controlling confounding variables and limiting potential biases used? 


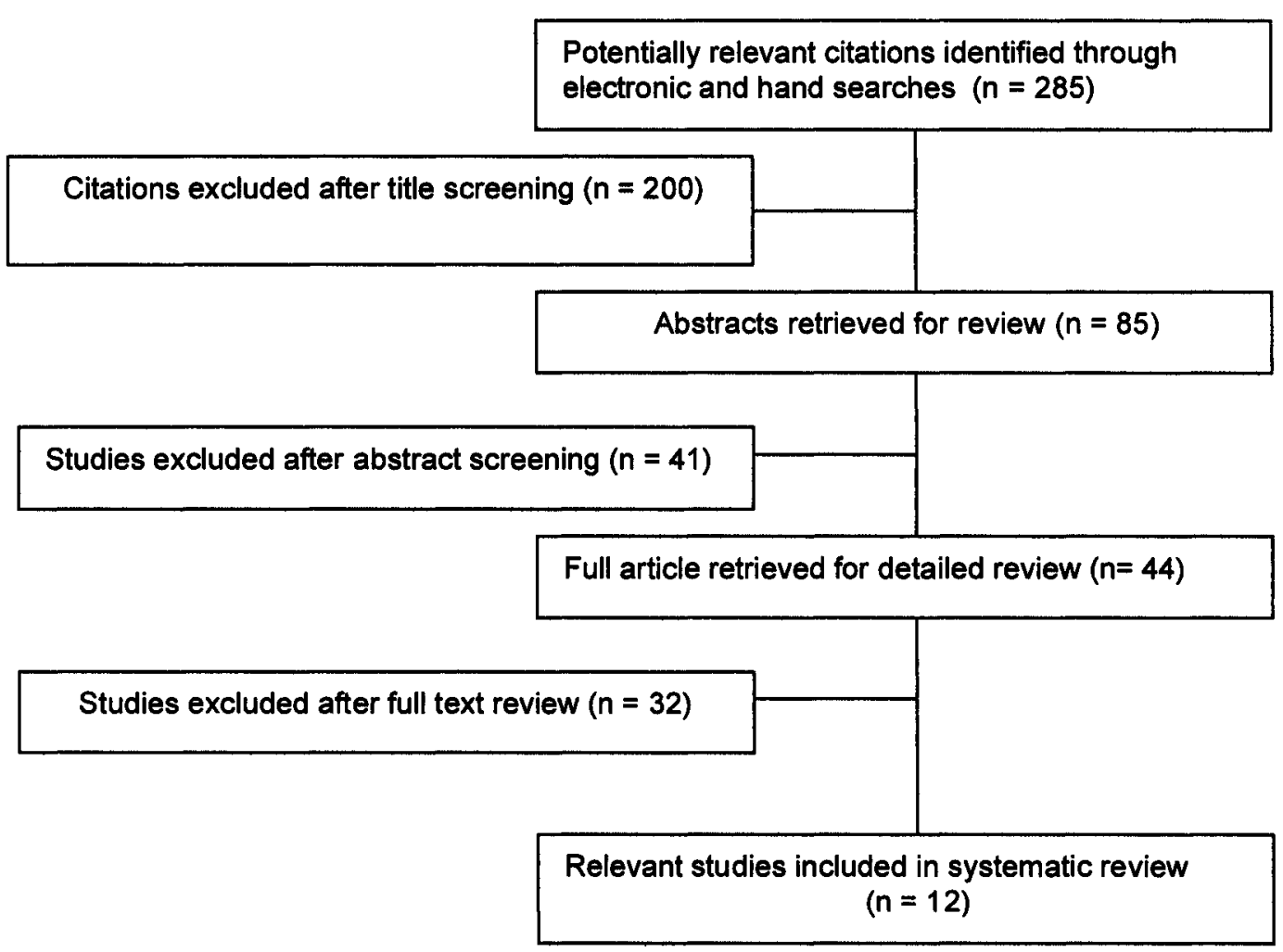

Fig. 1: Flow Diagram of Study Selection

\section{Data synthesis}

The diversity of study designs, interventions, and outcome measures predicated the use of qualitative rather than quantitative methods of data synthesis. Tabular summaries of participants, interventions, outcomes measured, direction of results, study design, level of evidence and study quality depict the state of research evidence emerging over the past 14 years.
RESULTS

The electronic database and manual search strategy identified 285 studies. Twelve studies met inclusion criteria forming the basis of this review. The numbers of exclusions at each stage of the screening process are depicted in Fig. 1. Reasons for exclusion were

- language other than English $(n=4)$,

- incomplete information $(n=1)$, 
- citations not intervention studies $(n=128)$,

- participants were not children with $\mathrm{CP}(\mathrm{n}=5)$,

- intervention not typical of physical therapy interventions $(n=72)$,

- co-interventions provided $(n=3)$, or

- outcomes measured did not include postural control $(n=60)$.

The 12 included studies comprised 10 group design studies and two single-subject studies. Except for the two studies by Myhr and colleagues (1991, 1995), all examined unique interventions and included a somewhat different mix of participants (see Table 4). A variety of age ranges and severity of children with CP participated in the studies. Across all studies, 132 children with $\mathrm{CP}$ were included (10 children participated in both Myhr et al. studies). Five general categories of physical therapy interventions were assessed, including seating devices $(n=5)$, balance training protocols or devices $(n=3)$, ankle-foot orthoses (n $=2$ ), motor therapy $(n=1)$, and Lycra garment ( $=1$ ). The level of evidence ranged from II to V, with four studies contributing Level II evidence, one contributing Level III evidence, six contributing Level IV evidence, and one contributing Level V evidence.

The study quality scores ranged from 2 to 7 , with a median score of 5.5 and a mode of 6 (see Table 3). Sixty-seven percent of the studies achieved a moderate or high quality score. A variety of postural control outcomes were addressed across the studies and a number of investigators explored additional outcomes, such as upper limb function, goal performance, and toy engagement (see Table 5). Measures of postural control across the studies were diverse with all but two using unique outcome measures (Myhr \& von Wendt, 1991; Myhr et al., 1995). The results of seven studies were positive for postural control outcomes. The highest levels of evidence (Level II) were obtained for two studies comparing adaptive seating interventions, both having significant results; one study of wedged shoes compared to solid anklefoot orthoses (AFOs) had non-significant results, and one study of neurodevelopmental therapy (NDT) compared to practice had non-significant results.

\section{DISCUSSION}

According to Barry (1996), "Clinicians have a responsibility to be familiar with current research and apply scientific evidence to their practice." Systematic reviews of efficacy and effectiveness studies provide an ideal model for clinicians to familiarize themselves with current research and to apply that evidence to their practice. In the area of postural control, the majority of studies have been observational, descriptive, or predictive, rather than experimental. Although these types of studies are critical to our basic understanding of postural control in children with $\mathrm{CP}$, they fail to answer the question of greatest importance to clinicians: Does my treatment make a difference?

As was true in the earlier review on postural control (Campbell, 1990), the majority (67\%) of the 12 'experimental' studies published since 1990 that were aimed at evaluating the effectiveness of physical therapy interventions on postural control provided lower levels of evidence, i.e. III to V. It appears, however, that in the 15 years since Campbell's review on the efficacy of postural control was published, little progress has been made in increasing either the quantity or the methodological rigor of designs for studies examining the effects of postural control interventions for children with $\mathrm{CP}$.

As Campbell stated in 1990, "Improvements in postural control, alignment, and stability have been reported in many research studies and most likely are true outcomes of physical therapy in children with CP. Definitive support is lacking however and 
S.R. HARRIS AND L. ROXBOROUGH

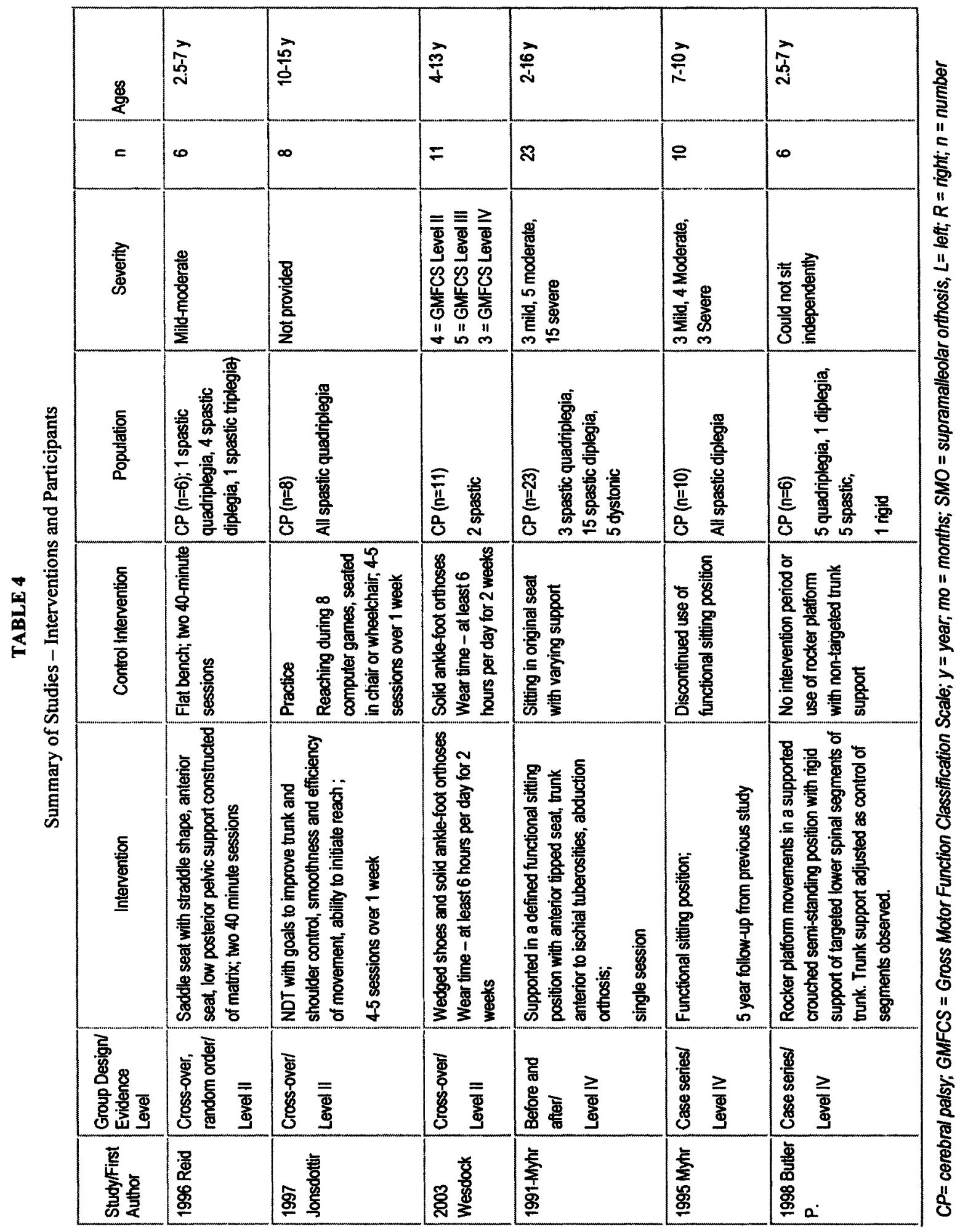




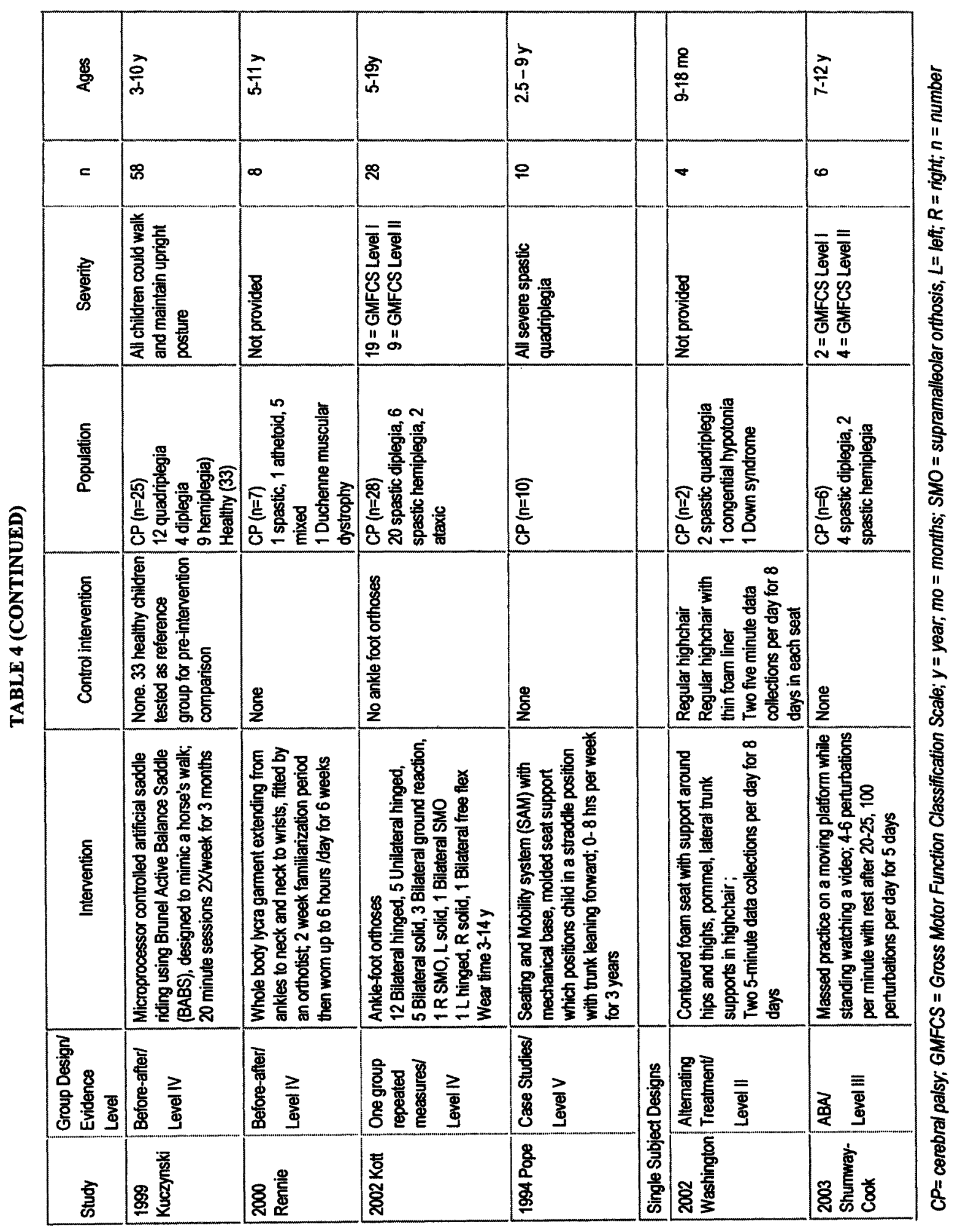


TABLE 5

Summary of studies: outcomes, measures, and results

\begin{tabular}{|c|c|c|c|c|}
\hline $\begin{array}{l}\text { Study } \\
\text { (date/first author) }\end{array}$ & $\begin{array}{l}\text { Evidence Levell } \\
\text { Study Quality }\end{array}$ & $\begin{array}{l}\text { Outcome of } \\
\text { interest }\end{array}$ & Measure & Results \\
\hline \multirow[t]{2}{*}{ Group Designs } & \multirow{5}{*}{ Level II (5) } & \multirow{4}{*}{$\begin{array}{l}\text { Postural } \\
\text { control } \\
\text { in sitting }\end{array}$} & $\begin{array}{l}\text { Sitting Assessment for Children with Neuromotor } \\
\text { Dysfunction- rest module }\end{array}$ & $p=.007 \ln t$ \\
\hline & & & Abnormal postural response & $p=.04 \operatorname{lnt}$ \\
\hline \multirow[t]{3}{*}{1996 Reid } & & & $\begin{array}{l}\text { 3-D sway stability- radius and path length of movement } \\
\text { traveled by marker placed on } C 7 \text { vertebra during a } 5 \\
\text { minute period sitting at rest }\end{array}$ & ns \\
\hline & & & Spinal extension & $p=.007 \mathrm{Int}$ \\
\hline & & $\begin{array}{l}\text { Upper extremity } \\
\text { movement control }\end{array}$ & Path length and movement units & ns \\
\hline \multirow{2}{*}{1997 Jonsdottir } & \multirow{2}{*}{ Level II (6) } & \multirow{2}{*}{$\begin{array}{l}\text { Postural control } \\
\text { in sitting }\end{array}$} & $\begin{array}{l}\text { Modified Posture Assessment Scale scored from video } \\
\text { (head, neck, shoulder, scapula and trunk items only) }\end{array}$ & $N s^{1}$ \\
\hline & & & $\begin{array}{l}\text { Kinematic analysis (WATSMART) of displacement of } \\
\text { the head and trunk during reach }\end{array}$ & ns \\
\hline \multirow[b]{2}{*}{2003 Wesdock } & \multirow[b]{2}{*}{ Level II (6) } & Standing balance & Duration of static standing measured in seconds & ns \\
\hline & & Knee extension & $\begin{array}{l}\text { Knee extension (measured with goniometer) sustained } \\
\text { for } 10 \text { seconds }\end{array}$ & ns \\
\hline \multirow{3}{*}{$1991 \mathrm{Myhr}$} & \multirow{3}{*}{ Level IV (6) } & $\begin{array}{l}\text { Postural control } \\
\text { in sitting }\end{array}$ & $\begin{array}{l}\text { Sitting Assessment Scale (head, trunk, foot control and } \\
\text { arm/hand function scored from video) }\end{array}$ & $p<001$ Int \\
\hline & & $\begin{array}{l}\text { Pathological } \\
\text { Movement }\end{array}$ & Number of pathological movements in 5 minute period & $p<.006$ Int \\
\hline & & Head control & Time head upright in 5 minute period & $p<.001$ int \\
\hline $1995 \mathrm{Myhr}$ & Level IV (3) & $\begin{array}{l}\text { Postural control in } \\
\text { sitting }\end{array}$ & Sitting Assessment Scale & $p<.05 \mathrm{Int}$ \\
\hline 1998 Butler P & Level IV (6) & $\begin{array}{l}\text { Independent } \\
\text { sitting balance } \\
\text { Segmental level of } \\
\text { control }\end{array}$ & $\begin{array}{l}\text { Independent sitting for } 30 \text { seconds } \\
\text { Area where control became deficient during static } \\
\text { sitting, a manual perturbation \& voluntary movement }\end{array}$ & $\begin{array}{l}\text { All improved } \\
\text { in } \\
\text { intervention } \\
\text { phase }\end{array}$ \\
\hline \multirow[t]{2}{*}{1999 Kuczynski } & \multirow[t]{2}{*}{ Level IV (2) } & Standing balance & Postural sway - centre of pressure movement & $p<.05 \mathrm{Int}$ \\
\hline & & & Auto-regressive modeling for feet-related displacement & ns \\
\hline
\end{tabular}

Abbreviations: $\mathrm{ns}=$ non-significant; Int = intervention group; $\mathrm{Ctl}=$ control condition or group; no dif = no difference; RSME = root mean square error; ${ }^{1} p<005$ In with one subject removed 
TABLE 5 (CONTINUED)

Summary of studies: Outcomes, measures, and results

\begin{tabular}{|c|c|c|c|c|}
\hline $\begin{array}{l}\text { Study } \\
\text { (Date/Author) }\end{array}$ & $\begin{array}{l}\text { Evidence Levell } \\
\text { Study Quality }\end{array}$ & $\begin{array}{l}\text { Outcome of } \\
\text { interest }\end{array}$ & Measure & Results \\
\hline \multirow[t]{2}{*}{2000 Rennie } & \multirow[t]{2}{*}{ Level IV (2) } & $\begin{array}{l}\text { Dynamic stability } \\
\text { in gait }\end{array}$ & $\begin{array}{l}\text { 3-D gait analysis - root mean square error for: } \\
\text { proximal stability index/distal stability index }\end{array}$ & ns \\
\hline & & Function & Pediatric Evaluation of Disability Inventory (PEDI) & $n s$ \\
\hline \multirow{5}{*}{2002 Kott } & \multirow{5}{*}{ Level IV (6) } & & Standardized walking Obstacle Course & \multirow[b]{2}{*}{ ns } \\
\hline & & Standing balance & Pediatric Balance Scale & \\
\hline & & Goal nerformance & Individualized anals & $50 \%$ no dif \\
\hline & & Goal pertormance & Individualized goals & $\begin{array}{l}18 \% \text { int } \\
8 \% \text { no dif }\end{array}$ \\
\hline & & Comfort & Subjective report & $\begin{array}{l}44 \% \text { CtI } \\
48 \% \ln \\
\end{array}$ \\
\hline \multirow{3}{*}{1994 Pope } & \multirow{3}{*}{ Level V (4) } & Sitting ability & Level of Sitting Scale & $\begin{array}{l}\text { Increased } \\
\text { one level }\end{array}$ \\
\hline & & & Body symmetry angle measure from photo & Maintained \\
\hline & & $\begin{array}{l}\text { Upper limb } \\
\text { function }\end{array}$ & Block task & unchanged \\
\hline \multicolumn{5}{|c|}{ Single Subject Designs } \\
\hline \multirow{3}{*}{2002 Washington } & \multirow{3}{*}{ Level II (7) } & Posture alignment & $\begin{array}{l}\text { Rating of midline alignment from video using markers as } \\
\text { visual guides }\end{array}$ & $\begin{array}{l}\text { All improved } \\
(p=.008 \text { int })\end{array}$ \\
\hline & & $\begin{array}{l}\text { Engagement with } \\
\text { toys }\end{array}$ & $\begin{array}{l}\text { Percentage of time hands on toy (scored from video) } \\
\text { Percentage of time hands free of support (scored from } \\
\text { video) }\end{array}$ & $\begin{array}{l}\text { No clear } \\
\text { effect }\end{array}$ \\
\hline & & Caregiving & Semi-structured parent interview (qualitative) & $\begin{array}{l}\text { Favored } \\
\text { intervention }\end{array}$ \\
\hline \multirow{2}{*}{$\begin{array}{l}2003 \text { Shumway- } \\
\text { Cook }\end{array}$} & \multirow[t]{2}{*}{ Level III (5) } & $\begin{array}{l}\text { Reactive balance } \\
\text { control in standing }\end{array}$ & $\begin{array}{l}\text { Centre of pressure } \\
\text { sway area per second } \\
\text { time to stabilization following a perturbation }\end{array}$ & All improved \\
\hline & & Motor function & Gross Motor Function Measure - Standing dimension & $\begin{array}{l}3 \text { of } 5 \\
\text { improved }\end{array}$ \\
\hline
\end{tabular}

Abbreviations: $\mathrm{ns}=$ non-significant; Int = intervention group; $\mathrm{Ctl}=$ control condition or group; no dif= no difference 
more research is needed." (p. 139). This statement was echoed five years later by Roxborough (1995) in her systematic review on adaptive seating, i.e. "additional studies with stronger designs" are needed to establish that our postural control interventions for children with $\mathrm{CP}$ are making a difference.

Unfortunately, 10 to 15 years later these statements are still generally true, although the quality scores for the 12 studies reviewed in the current paper are encouraging, with $67 \%$ receiving 'moderate' or 'strong' scores ( 5 to 7 of a possible total score of 7). Also encouraging is the finding that Level II evidence is emerging for adaptive seating interventions having a positive impact on postural control. In contrast, the previous review of adaptive seating (Roxborough, 1995) found only one (Level III) study that examined a postural control outcome. The features of adaptive seating common to all five studies in the current review were stabilization of the pelvis in a slightly anterior-tilted position and increasing the sitting base by supporting the thighs in flexion and abduction. This strategy likely optimized the starting conditions for movement by increasing the base of support and providing a stable origin for the trunk and lower extremity muscles. Improved postural control in sitting was evident during short-duration intervention (Myhr \& von Wendt, 1991; Reid, 1996), moderate-duration intervention (Washington et al., 2002), and persisted into the three-year (Pope et al. 1994) and five-year (Myhr et al, 1995) follow-up studies. Future studies of adaptive seating should explore the impact of postural control changes on functional abilities and the impact of seating device use on the development of independent sitting. One potential limitation in comparing the 1995 review to the current review is that Sackett (Sackett, 1986; Sackett et al, 2000) has modified his levels of evidence in the interim.

Three studies examined the effect of interventions comprising externally generated movement on development of postural control (Butler P, 1998; Kuczynski \& Slonka, 1999; Shumway-Cook et al, 2003). In a Level II single-subject study, Shumway-Cook and colleagues (2003) demonstrated improved reactive balance responses in standing after intensive sessions of platform perturbations over a 5-day period. The improvement was sustained over the 30-day follow-up period. Using computergenerated saddle movements in a Level IV group design, Kuczynski and Slonka (1999) demonstrated improved postural sway parameters when assessing standing balance following a 3-month intervention study. In another Level IV group study, Penelope Butler (1998) used a rocker platform to provide movement while the subjects were positioned in a semi-upright position with targeted support applied to the trunk. The trunk support was adjusted as control improved and movements were generated by both the therapist and the child. These two Level IV studies provide suggestive evidence for the effectiveness of the interventions. Considered together with the former Level II study, postural perturbations show promise for improving some aspects of postural control, particularly reactive balance when a high number of repetitions is provided. The results of these studies have recently been translated into clinical intervention suggestions (Westcott \& Burtner, 2004) incorporating practice in reacting to external perturbations with high repetitions.

Two studies examined the effects of lower extremity orthoses on standing balance (Kott \& Held, 2002; Wesdock \& Edge, 2003). Wesdock and Edge (2003) showed no difference in duration of static standing between the use of wedged shoes with AFOs vs. AFOs alone in their Level II study. In a Level IV study, Kott and Held (2002) demonstrated no difference in performance with or without AFOs on the Pediatric Balance Scale or a Standardized Obstacle Course even though subjects had been using their solid or hinged orthoses for three to fourteen years. Although relatively strong 
evidence (Level II) indicates that wedged shoes confer no advantage over AFOs alone, additional studies of stronger design (Levels I to III) are required to confirm or refute the finding of no difference between AFOs and no orthoses on postural control outcomes.

One Level IV study examined the effect of whole-body Lycra garments on dynamic stability during gait (Rennie et al., 2000). Although no statistically significant difference was found in the stability index (root mean square error) with and without the Lycra garments, the authors reported a trend toward improved proximal stability, noting that the study may have lacked the power to detect a clinically important difference because of the small sample size. Further research with a larger sample and stronger design can provide definitive evidence for the effectiveness of this intervention. Nevertheless, the feasibility of this intervention should first be examined based on an additional study finding that seven of the eight parents would not consider continuing garment use.

A Level II study examining the effects of one week of NDT or one week of practice found no significant effect of either intervention on postural control in sitting, as measured by the Modified Posture Assessment Scale, or kinematic analysis of displacement of the head and trunk during reach (Jonsdottir et al., 1997). That study contributes moderately strong evidence for the lack of effects of either intervention at the group level following the short intervention period. The authors did report, however, a substantial variability in the individual responses of five of eight children in the NDT group showing improved postural alignment. Additional research is thus required to determine whether some subsets of children with $\mathrm{CP}$ respond better to NDT-based or practice-based interventions than others do. The Gross Motor Function Classification System (Palisano et. al, 1997) can be useful to identify subgroups for future studies and to allow a comparison of sub-groups across studies. The study results are consistent with the findings of a systematic review of the research on neurodevelopment therapy that found conflicting evidence for the effects of NDT on motor impairments (Butler \& Darrah, 2001).

The present review has several limitations in addition to the one mentioned previously. As only English language articles were included, the review is likely not a complete picture of the available evidence for this topic. Because the review was limited to research papers that had been published, studies that have been conducted but not submitted or accepted for publication may also have been missed, and therefore the conclusions could be affected by publication bias. Publication bias is the tendency for researchers or publishers to submit or publish articles based on the direction or strength of the results (Dickerson, 1990). The recent survey of presenters at the Society for Pediatric Research meetings conducted by Hartling and colleagues (Hartling et al. 2004) indicates that many studies are still not being submitted for publication. An additional limitation of the review is the possibility of missing studies having postural control outcomes embedded within other outcome measures, such as motor function measures or gait measures.

\section{CONCLUSIONS}

In their review article on postural control, Westcott and Burtner (2004) stated that the most important goal of future postural control interventions is to gear treatments toward changing functional motor performance that will provide carryover into meaningful activities of daily living and recreational activities for children with neuromotor disabilities. We believe that our clinician colleagues have the responsibility to lead the way in designing and conducting future studies to examine the effects of their postural control interventions on functional outcomes in the 
children they serve. Furthermore, we hope that this systematic review will provide a 'jumping off' point for clinicians and clinical researchers to evaluate further the efficacy and effectiveness of postural control interventions on the functional and recreational activities of children with $\mathrm{CP}$.

\section{REFERENCES}

Barry M. 1996. Physical therapy interventions for patients with movement disorders due to cerebral palsy. J Child Neurol 11 Suppl 1: S51-S60.

Boyd R, Hays R. 2001. Current evidence for the use of botulinum toxin type $A$ in the management of children with cerebral palsy: a systematic review. Eur J Neurol 8 Suppl 5: 1-20.

Brogren E, Forssberg H, Hadders-Algra M. 2001. Influence of two different sitting positions on postural adjustment in children with spastic diplegia. Dev Med Child Neurol 43: 534-546.

Brogren E, Hadders-Algra M, Forssberg H. 1998. Postural control in sitting in children with cerebral palsy. Neurosci Biobehav Rev 4: 591-596.

Butler C. 1998. AACPDM methodology for developing evidence tables and reviewing treatment outcome research. American Academy for Cerebral Palsy and Developmental Medicine, www.aacpdm.org

Butler C, Darrah J. 2001. Effects of neurodevelopmental treatment (NDT) for cerebral palsy: An AACPDM evidence report. Dev Med Child Neurol 43: 778-790.

Butler PB. 1998. A preliminary report on the effecttiveness of trunk targeting in achieving independent sitting balance in children with cerebral palsy. Clin Rehabil 12: 281-293.

Campbell SK. 1990. Efficacy of physical therapy in improving postural control in cerebral palsy. Pediatr -Phys Ther 2: 135-140.

Dickerson K. 1990. The existence of publication bias and risk factors for its occurrence. JAMA 263: 1385-1389.

Hammell KW, Carpenter C. 2004: Qualitative Research in Evidence-Based Rehabilitation. Edinburgh, Scotland: Churchill Livingstone; 138.

Hartling L, Craig WR, Russell K, Stevens K, Klassen TP. 2004. Factors influencing the publication of randomized controlled trials in child health research. Arch Pediatr Adolesc Med 158: 1014-1015.
Horak FB. 1992. Motor control models underlying neurologic rehabilitation of posture in children. In: Forssberg H, Hirschfeld $\mathrm{H}$, eds, Movement Disorders in Children. Basel, Switzerland: Karger; 21-30.

Jonsdottir J, Fetters L, Kluzik J. 1997. Effects of physical therapy on postural control in children with cerebral palsy. Pediatr ihys Ther 9: 68-75.

Kott KM, Held SL. 2002. Effects of orthoses on upright functional skills of children and adolescents with cerebral palsy. Pediatr Phys Ther 14: 199-207.

Kuczynski M, Slonka K. 1999. Influence of artificial saddle riding on postural stability in children with CP. Gait Posture 10: 154-160.

Massion J. 1998. Postural control systems in developmental perspective. Neurosci Biobehav Rev 22: 465-472.

Myhr U, von Wendt L. 1991. Improvement of functional sitting position for children with cerebral palsy. Dev Med Child Neurol 33: 246-256.

Myhr U, von Wendt L, Norrlin S, Radell U. 1995. Fiveyear follow-up of functional sitting position in children with cerebral palsy. Dev Med Child Neurol 37: 587-596.

Palisano R, Rosenbaum P, Walter S. Russell D, Wood E, Galuppi B. 1997. Development and reliability of a system to classify gross motor function in children with cerebral palsy. Dev Med Child Neurol 39: 214-223.

Pope PM, Bowes CE, Booth E. Postural control in sitting. The SAM system: Evaluation of use over three years. Dev Med Child Neurol 1994. 36: 241252.

Portney LG, Watkins MP. 2000. Foundations of Clinical Research: Applications to Practice, $2^{\text {nd }}$ edition. Upper Saddle River, New Jersey, USA: Prentice Hall Health; 743.

Reid DT. 1996. The effects of the saddle seat on seated postural control and upper-extremity movement in children with cerebral palsy. Dev Med Child Neurol 38: 805-815.

Rennie DJ, Attfield SF, Morton RE, Polak FJ, Nicholson J. 2000. An evaluation of Lycra garments using 3D gait analysis and functional assessment (PEDI). Gait Posture 12: 1-6.

Roxborough L. 1995. Review of the efficacy and effectiveness of adaptive seating for children with cerebral palsy. Assist Technol 7: 17-25.

Sackett DL. 1986. Rules of evidence and clinical recommendations on the use of antithrombotic agents. Chest 89: 25-35. 
Sackett D, Strauss S, Richardson S, Rosenberg W, Haynes R. 2000. Evidence-based Medicine: How to Practice and Teach EBM. Second Edition. Edinburgh, Scotland.

Shumway-Cook A, Hutchinson S, Kartin D, Price R, Woollacott M. 2003. Effect of balance training on recovery of stability in children with cerebral palsy. Dev Med Child Neurol 45: 591-602.

Shumway-Cook A, Woollacott M. 1993. Theoretical issues in assessing postural control. In: Wilhelm IJ, ed, Physical Therapy Assessment in Early Infancy. New York, NY, USA: Churchill Livingstone; 161 171.

Siebes R, Wijnroks L, Vermeer A. 2002. Qualitative analysis of therapeutic motor intervention programmes for children with cerebral palsy: an update. Dev Med Child Neurol 44: 593-603. van der Heide JC, Beeger C, Fock JM, Otten B, Stremmelaar E, van Eykern LA, et al. 2004. Postural control during reaching in preterm children with cerebral palsy. Dev Med Child Neurol 46: 253-266.

Washington KA, Deitz JC, White OR, Schwartz IS. 2002. The effects of a contoured foam seat on postural alignment and upper-extremity function in infants with neuromotor impairments. Phys Ther 82: 1064-1076.

Wesdock KA, Edge AM. 2003. Effects of wedged shoes and ankle-foot orthoses on standing balance and knee extension in children with cerebral palsy who crouch. Pediatr Phys Ther 15: 221-231.

Westcott SA, Burtner P. 2004. Postural control in children: Implications for pediatric practice. Phys Occup Ther Pediatr 24: 5-55. 

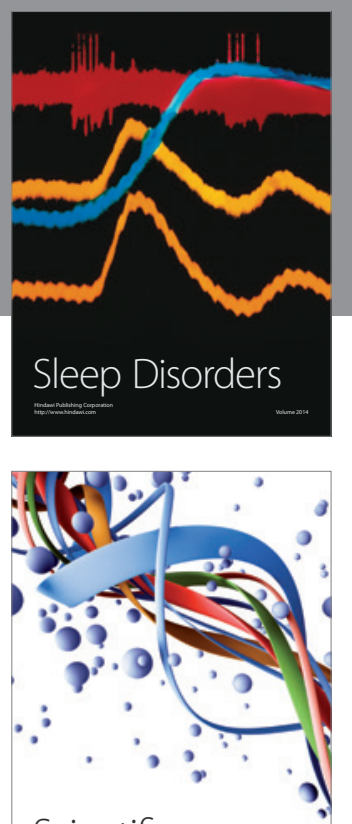

Scientifica
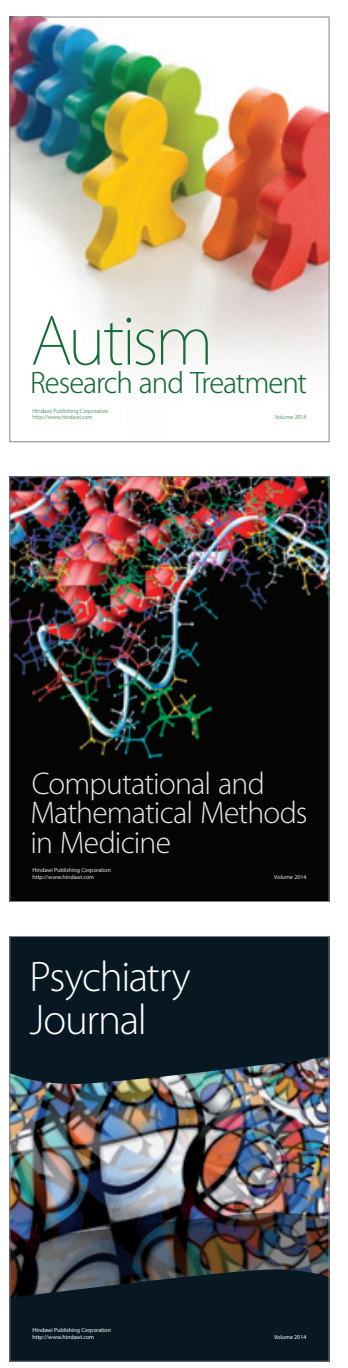
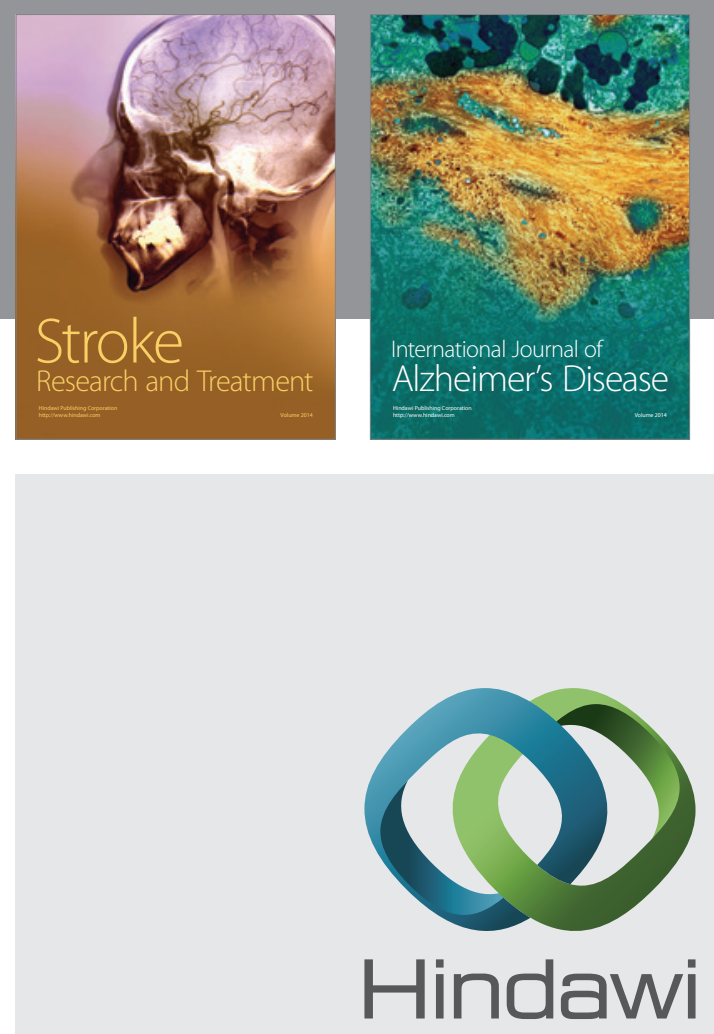

Submit your manuscripts at

http://www.hindawi.com
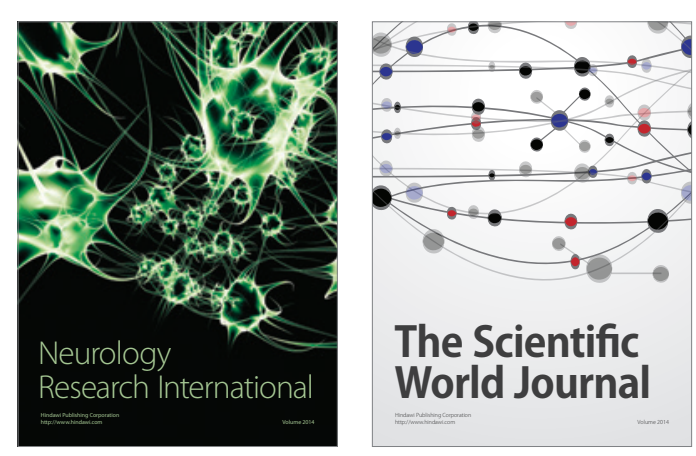

The Scientific World Journal

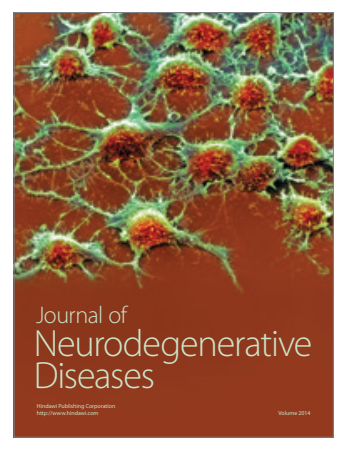

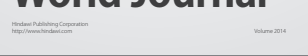

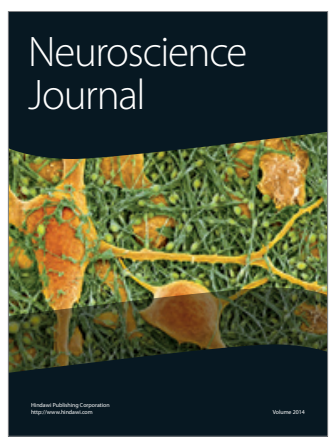

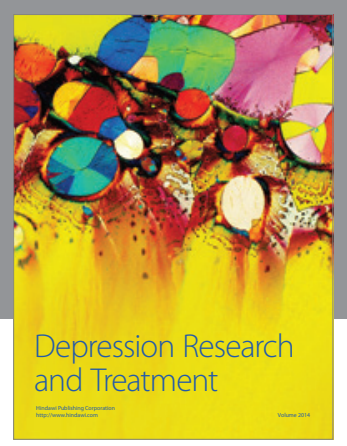
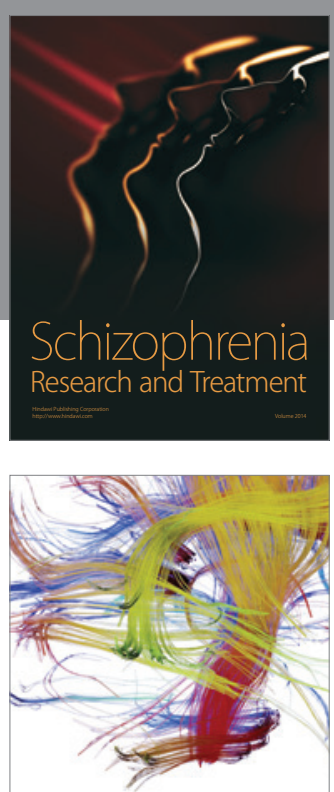

Brain Science

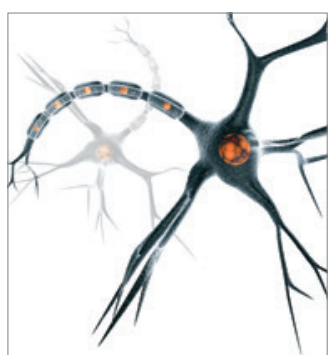

Neural Plasticity
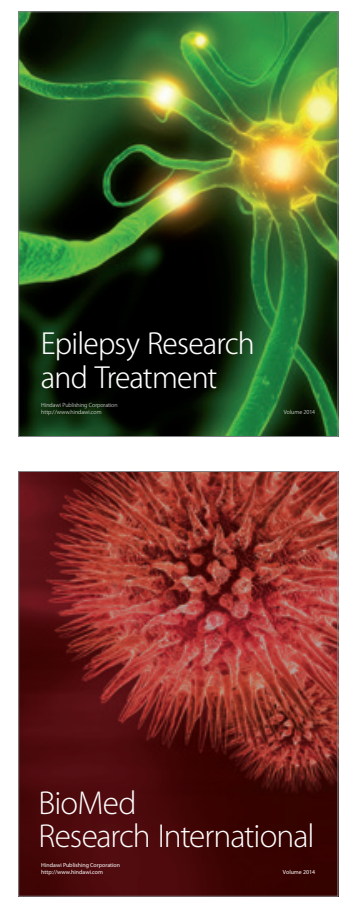

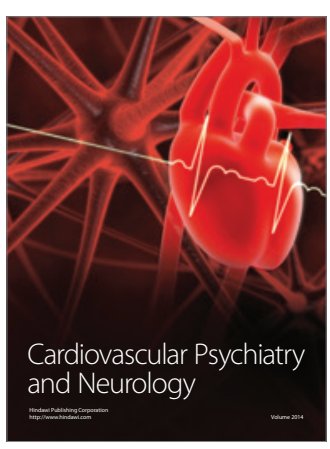

Parkinson's

Disease
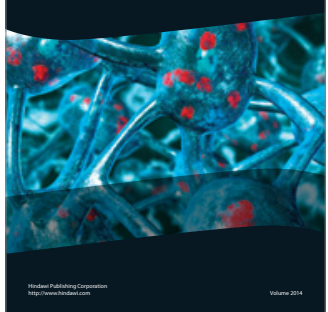